\title{
Las ideas de Mitre sobre el Municipio
}

\author{
por \\ CARLOS MOUCHET \\ Director General de Asuntos Legales de la Municipalidad de Buenos Aires
}

\section{Mitre municipalista}

Bartolomé Mitre formó parte de una generación municipalista, junto a Echeverría, Alberdi, Sarmiento, Florencio González, Estrada y tantos otros hombres de su época, que creyeron en la excelencia del régimen municipal como una de las bases esenciales de la reorganización de la República Argentina después del gobierno de Rosas, y como uno de los medios nocesarios para la subsistencia y progreso de la libertad politica.

Esta generación recibió la influencia de las ideas sobre el Municipio contenidas en el famoso libro de Tocqueville Lä democracia en América, publicado entre los años 1834 y 1840 . El gran mérito de esta influencia reside en responder a una concepción natural e histórica del Municipio. Nuestros abuelos presenciaban el desárrollo de una democracia tumu'tuosa, cuyo equilibrio estaba todavía más en las leyes que en las costumbres. Les preocupó la perspectiva seña!ada por Tocqueville de que en las repúblicás americanas la omnipotencia de las mayorias podía llevar paradójicamente a la tiranía. Por ello, les sedujo con la idea de que las Corporaciones municipales eran una forma de dividir los peligros de la vo'untad centralizadora. También les mostró las dificultades para establecer y defender las instituciones munici- 
pales. "Entre todas las libertades - decía - las de las Comunas que tan dificilmente se establece, es también la que más 'expuesta se halla a las invasiones del poder". Y en la Argentina los contemporáneos sabrán apreciar la exactitud de esta frase de Tocqueville: "Una sociedad muy civilizada, sólo con pena tolera los ensayos de la libertad comunal; se irrita con el espectáculo de sus numerosos extravíos, y desespera del buen éxito antes de haber alcanzado el resultado final de la experiencian. Y agregaba: "Mientras la libertad comunal no haya entrado en las costumbres, es fácil destruirla, y sólo puede entrar en las costumbres después de haber subsistido mucho tiempo en las leyes..." (1).

El Cabildo y el Municipio posterior a 1853 atrajeron la atención de Mitre como historiador y como hombre de gobierno. Además de comprender el papel que desempeñan la's ciudades y las instituciones municipales en la dinámica historia, advirtió la persistencia de lo municipal como un producto natural de la vida en sociedad.

Reconoció el papel cumplido por los Cabildos hispano-india- nos como instituciones de sentido popular, y estudió documentadamente la intervención de los mismos, principalmente el de Buenos Aires, en dos acontecimientos revolucionarios del Río de la Plata y en el proceso político posterior, hasta su disolución alrededor de $\mathbf{1 8 2 0 .}$

Por otra parte, después de Caseros lo vemos señalando concretamente la función fundamental que debían cumplir las Municipalidades en la reorganización política y administrativa del país, y en particular en la Provincia de Buenos Aires, cuya situación atraía en esos momentos sus afanes.

Sus ideas sobre la materia, dispersas en su magna obra de publicista y de hombre de gobierno, deben buscarse principalmente en los siguientes trabajos:

1) En los capítulos VII, IX y X dei tomo I y en el capítulo XLII del tomo III de la Historia de Belgrano. En el tomo I

(1) Tocquevilse, De la democracia en América, trad. de E. Chao. Madrid, 1854, página 44. 
se ocupa de los Cabildos abiertos españo'es de Montevideo y de los de 1810 en Buenos Aires, y en el tomo III realiza un bosquejo históricos sobre los Cabildos.

2) En la Historia de San Martín están dedicados al Cabildo indiano y patrio varios capítulos del tomo $I$, los que se indican a continuación: capítulo I, La colonización hispano-amricana; capítulo VII, Los Cabildos de Santiago y Buenos Aires; capitulo IX, Revolución municipal en Cuyo. Además, se ocupa de los Cabildos de Cuyo bajo el gobierno de San Martín.

3) En sus artículos titulados El gobierno propio publicado en "El Nacional” de Buenos Aires del 20 de octubre de 1852 y La reorganización de las $M$ unicipalidades, aparecido è el mismo periódico el 22 de noviembre de 1853.

4) En sus discursos en la Asamblea constituyente del Estado de Buenos Aires (sesión del 2 de marzo de 1854) y en la Convención reformadora de la Constitución de la Provincia de Buenos Aires (sesión del 4 de julio de 1871).

5) En referencias de otros artículos y trabajos como los que constituyen su Profesión de fe, publicada en el diario viLos Debates" a partir del $10^{\circ}$ de abril de 1852.

\section{El Cabildo hispano-indiano}

Mitre, buen conocedor del pasado hispano-indiano y de las Leyes de Indias (2), examinó e interpretó el fenómeno del trasplante y florecimiento en América de las decadentes instituciones municipales españolas. Le fué precisa esta investigación para explicar la razón de su preponderante intervención en los acontecimientos revo'ucionarios antes y después de 1810.

"Los Cabildos americanos-dice en la Historia de Belgrano-

(2) Ver Raill A. Molina, Mitre, investigador. Urigen de los documentos de su archivo colonial, y José TORRE REvezlo, Algunas referencias sobre la correspondencia de Bartolomé Mitre acerca de iibros y documentos, trabajos publicados e) el volumen titulado eMitre. Homenaje de la Academia Nacional de la Historia en el cincuentenario de su muerte (1906-1956)d, Buenos Aires, 1906. 
no tuvieron su antiguo significado ni su importancia política; pero en razón de la distancia y las necesidades elementales del gobierno, los reyes absolutos les concedieron más franquicias reales que a los que por el mismo tiempo funcionaban en la Península. A esto y a ser la única institución popular, debieron la importancia que gradualmente fueron adquiriendo hasta identíficarse con la nueva sociabilidad. Con la tradición histórica de las arrogantes comunidades de Toledo y de Aragón en el pasado, con la ficción de una elección popular por título, y el nombre de república esculpido en sus blasones cívicos, esas corporaciones ejercian funciones de propio gobierno, en cuanto a la gestión de los intereses comunes y a la administración de la justicia ordinaria. Representantes del pueblo, en teoría, tenían el derecho de convocarlo a son de campana; reunirio en congreso para deliberar, como en las democracias de la antigüedad sobre sus propios negocios; levantar tropas comunales; crear contribuciones; poner en posesión a los gobernadores nombrados por la Corona y recibirles el juramento; y en ocasiones solemnes, erigirse legalmente en poderes independientes, invocando sus fueros y los derechos de los ciudadanos del Municipion (3).

En uno de sus discursos reconocía que, aunque el pueblo no concurría a su composición, el Cabildo entrañaba, especialmente mediante los Cabildos abiertos, "un principio democrático y de libertad que debia dar con el tiempo el fruto que en la Madre Patria no había podido producir". También recordaba que "España, como lo confiesan los ingleses y declara Lieber, que hace justicia a los ingleses y españoles, tuvo antes que Inglaterra la inteligencia y la conciencia de las instituciones libres del propio Gobierno, implantadas en las instituciones feudales y la autonomía del Municipio. Los comuneros vencidos con Padilla en Villalar, formaron un programa de gobierno constitucional más adelantado que la Carta Magna de los ingleses, y los Fueros de

(3) Historia de Belgrano, en cObras completas», Buenos Aires, 1941, volumen VIII, págs. 342-13. 
Aragón y de Vizcaya contenían gérmenes que sólo la tirania podia esterilizar en la tierra de su nacimiento. Carlos $\mathrm{V}$ y Felipe II, con ia fuerza brutal de la autoridad absoluta, sofocaron esas instituciones que han dado a la Inglaterra la base sólida de sus libertades conquistadas" (4). Hay coincidencia entre Mitre y Sarmiento en esta comparación de las instituciones municıpales hispanas con las inglesas (5).

\section{Papel del iCabildo en la Revolución e independencia} ARGENTINA

La actitud de los Cabildos en los acontecimientos de la independencia argentina tiene su explicación en la propia naturaleza de los mismos y en las funciones que cumplían dentro de la organización del imperio español en Indias. Dice Mitre que ula localidad ganó terreno por medio de estas corporaciones; el espíritu público se educó en esta escuela primaria del propio Gobierno, inoculándose a ellas desde entonces la revolución futura que los Ayuntamientos guardaron en su seno..." (6).

Este papel revolucionario comienza en Buenos Aires y en Montevideo con las invasiones inglesas. "El Cabildo de Buenos A.ires-recuerda Mitre-asumió el carácter de una verdadera asamblea política, después de haber presidido a la defensa del

(4) En la Convención Constituyente de Buenos Aires de 1571. Ver Debates de la Convención Constituyente de Buenos Aires, publicación oficial hecha bajo la dirección del convencional Luis L. Varela, Buenos Aires, 1S7T, tomo I, páginas 369 y ss. También se refiere al régimen municipal en Debates, tomo II, páginas 948 y ss.

(5) Ver Carlos Mouchet, Pasado y restauración del régimen municipal, Buenos Aires, 19007, págs. 33 y ss. Acerca del pensamiento municipal antes de la Independencia, ver C. Mouchet, Las ideas sobre el Municipio en el periodo hispano-indiano, en aRevista del Instituto de Historia del Derecho», Buenos Aires, núm. 7, año 195̄̄-56, págs. 65̃ y ss.

(6) En el articulo citado sobre La.reorganización de las Municipalidades de La Provincia. 
Municipio, contribuyendo a la deposición de un Virrey, y dictando nuevas reglas de gobierno...) (7).

Los Cabildos abiertos adquieren, por obra de los propios españoles, una forma revolucionaria evidentemente no prevista en las Leyes de Indias.

Los españoles dan tal fisonomía all Cabildo abierto de Montevideo del 21 de septiembre de 1808 , desconocedor de la nueva autoridad virreinal de Buenos Aires, y que formó una Junta gubernativa local, dando así un ejemplo que había de serles funesto, pues, a su vez, los criollos utilizaban el mismo sistema para destituir autoridades hispanas.

Lo advirtió la Audiencia de Buenos Aires en un dictamen redactado por el perspicaz Fiscal Dr. Cañete, que condenó ese movimiento a la luz del Derecho vigente. "El procedimiento del Cabildo de Montevideo-expresaba-puede ocasionar la ruina de estas Provincias, la absoluta subversión de nuestro gobierno, el trastorno de su sabia constitución, que indudablemente conduciría al precipicio". "He ahí-agrega Mitre-la revolución de la Independencia presentida por los intérpretes del Derecho colonial y los depositarios de la suprema autoridad judicial y política de América..." (8).

E! Cabildo de Buenos Aires, en actitudes revolucionarias, destituye dos Virreyes el 14 de agosto de 1806 , y el 22 de mayo de 1810. Esta intervención política la realizan los Cabildos excediéndose de su competencia, lo que, convertido más tarde en práctica, habría de originar, a la postre, la ruina de la institución.

Pocos han señalado con tanta elocuencia como Mitre el papel del Cabildo de Buenos Aires en los acontecimientos revolucionarios de 1810. Al referirse al Cabildo abierto del 22 de mayo, expresa que fué "la primera asamblea popular que inauguró la libertad y proclamó los derechos del hombre en la patria de los argentinos. El 22 de mayo de $\mathbf{1 8 1 0}$ es el día inicial de la Revolución argentina, con formas orgánicas y propósitos deliberados".

(7) Historia de Belgrano, en ¿ Obras completas», vol. VIII, pág. B44.

(8) Historia de Belgrano, en abras completas», tomo VI, pág. 2̄0. Ver también tomo $\mathrm{X}$, pág. 247 . 
Las reglas dictadas por el Cabildo de Buenos Aires constituyen, al decir de Mitre, da primera constitución política que tuvo el pueblo argentino" (9).

También se ocupa de la actividad revolucionaria de los $\mathrm{Ca}$ bildos del interior. E1 gobierno municipal de Cuyo le merece palabras de encomio, pues constituye uno de los factores favorables que permitió a San Martín la preparación de su ejército libertador. Mendoza, San Juan y San Luis respondieron de inmediato al movimiento iniciado en Buenos Aires en mayo de 1810. Y el Cabildo de Mendoza of reció a San Martín pruebas notables de generosidad y estima personal, que la gratitud nacional no puede olvidar.

San Martín encuentra en Cuyo una sencilla, aunque efectiva, vida municipal. "El gobierno de Cuyo-dice Mitre-era esencialmente municipal. Cada una de las tres ciudades tenia un Cabildo que ila regía en lo administrativo, judicial y policial, y jos cuarteles en que se subdividia cada Municipio estaban a cargo de funcionarios llamados decuriones, que eran sus jueces de paz. Así, las poblaciones aglomeradas en reducidos espacios se hallaban bajo la inmediata vigilancia de una autoridad paternal, que conocía el carácter y el haber de cada habitante, de modo que podia establecer su filiación moral y el inventario de todas las fortunas en veinticuatro horas". "Sin este estado analítico sobre la sociabilidad cuyana-agrega Mitre-, no se comprendería cómo San Martín pudo emprender y llevar a término, con organización tan rudimentaria, tan pobres recursos y tan corto número de habitantes, la ardua y hasta entonces imposible empresa de crear un ejército invencible, alimentado por el espacio de tres años con la sustancia de una sola Provincia, tomar por la primera vez la ofensiva en la guerra sudamericana y libertar dos repúb.icas, dando expansión continental a la revolución argentina” (10).

(9) Historia de Belgrano, en CObras completasø, tomo VI. págs. 328 y 342.

(10) Historia de Son Martin, en eUbras completass, vol. II, págs. 75-78. 


\section{Justificación por Mitre de la supresión de los Cabildos}

La mirada aguda de Mitre ve en la caíla de los Cabildos, después de cumplida su misión revolucionaria, el simbolo de la extinción del régimen ucolonial". "El año 20-expresa-fué la tumba de los Cabildos. Este año, que se ha considerado solamente como el período de la anarquía, señala la transición de dos épocas, la muerte de un sistema y el nacimiento de un nuevo orden de cosas. Desde 1810 hasta 1820 vivimos bajo el régimen representativo municipal. Desde 1820 entramos en el sendero del régimen representativo republicano. Antes los Cabildos habían sido las asambleas políticas, los cuerpos deliberantes, como hoy to son las legislaturas provinciales". "Los Cabildos-agrega-, desde entonces, desaparecieron de la escena politica, para dar su lugar a las nuevas instituciones, dejando, sin embargo, un vacío que sólo las Municipalidades pueden llenar» (11).

Como después lo hizo Sarmiento (12), justifica en parte a Rivadavia, inspirador de la Ley del 25 de diciembre de 1821, que suprimió los Cabildos de la Provincia de Buenos Aires (13). Esta Ley, según Mitre, no hizo sino "consagrar un hecho", y el "error

(11) En el articulo La reorganización de las Municipalidades de la Provincia, citado. Mitre repite y desarrolla estos conceptos en el capitulo XILIII del tomo III de la Historia de Belgrano, en wObras completasn, vol. VIII, págs. 366 y s:guientes. Expresa Ricardo Levene que la llamada anarquia del año 20 ano es sino la Revolución de Mayo en marcha, que recobra su ritmo originario después de periodos de abatimiento o de transición con el pasado virreinal superviviente en la historia patria, pero que hace su crisis fecunda diez años después. Se destruyeron las jerarquias políticas de las Intendencias, de cuyo seno nacen las Provincias y se abolieron los Cabildos, es decir la cuna de las Juntas dc Representantes» (Historia del Derecho argentino, Buenos Aires, 1949, t. V, página 273).

(12) Ver Carlos Mouchet, Pasado y restauración del régimen municipal, Buenos Aires, 1057, págs.

(13) Ver Carlos Mouchet, El centenario de la Ley de Municipalidades de la crovincia de Buenos Aires de 1854, en revista cLa Ley», Buenos Aires, t. T7, página 771. Aquí se registran los antecedentes de da supresión de los Cabildos de Buenos Aires y la discusión en la Sala de Representantes entre Rivadavia y Valentin Gómez. 
no estuvo en destruir los Cabildos, que habían llegado a ser elementos de desorden, sino en no reemplazarlos con verdaderas Municipalidades". El error estuvo en centralizar el poder "atribuyendo al Gobierno todas las atribuciones municipales, que hasta hoy conserva, con grave perjuicio de los intereses públicos" (14). Mitre tuvo oportunidad de recordar la acción municipal-que sin Municipalidad y desde el ejecutivo-impulsó Rivadavia en la ciudad de Buenos Aires (15). Ello explica la aparente anomalía de que en el "hall" del palacio municipal de la ciudad de Buenos Aires luzca el busto de Rivadavia.

\section{Misión de las Municipalidades en la Reorganización de la Provincia de Buenos Aires}

Durante los años 1852 a $\mathbf{1 8 5 4}$, en medio de agitados acontecimientos políticos y militares, el restablecimiento de las Municipalidades se planteó como uno de los grandes problemas que debía afrontar la nación en su nueva etapa histórica.

El proceso de desaparición de los Cabildos en todo el territorio de las Provincias Unidas del Río de la Plata, había comenzado en Entre Ríos en 1820, culminando en 1821 con la abolición de los Cabildos de la Provincia de Buenos Aires, y terminado en Jujuy en 1837 (16). Después de esta fecha no funcionaron instituciones municipales en el país. Como contraste de esa ausencia, hubo un florecimiento de ideas municipalistas en Echeverría y Alberdi, de las que nos hemos ocupado en otro trabajo (17).

(14) En el articulo La reorganizacion, etc.

(15) En el centenario de Rivadavia. Oración fúnebre en la Plaza de la Victoria, el 20 de mayo de 1880 (Arengas selectos, Buenos Aires, s. d., página 187).

(16) Ver José Maria Sáez Valiente, La abolición de los Cabildos argentinos. Cuóndo y cómo se produjo, en la aRevista del Colegio de Abogados» de Buenos Aires, 1945, núm. 1, pág. 3.

(17) Carlos Mouchet, Las ideas de Echeverria, Alberdi y los constituyentes de 1853 sobre el régimen municipal, en revista oLa Ley,, Buenos Aires, t. 84, octubre. diciembre, 1956 , pág. 640 . 
E1 General Urquiza, Presidente provisional de la Confederación Argentina, dicta, el 2 de septiembre de 1852, un Decreio estableciendo la creación de la Municipalidad de la ciudad de Buenos Aires. Dicho Decreto, que no llegó a cumplirse, va precedido de un preámbulo en que se desarrolla una concepción definida de la institución, dentro de la gradación Familia-MunicipioEstado. Pretendía ensayar el sistema municipal en la ciudad de Buenos Aires como ejemplo para las demás ciudades de la nación, a fin de demostrar "prácticamente la bondad del sistema municipal, que consiste en dejar los negocios peculiares a la libre administración de los que tienen más intereses en ellos y más capacidad de dirigirlos".

En los estadistas y escritores de la Provincia de Buenos Aires existía análoga preocupación. El diputado Estévez Seguí presentó a la Legislatura, el 5 de octubre de 1852, un proyecto sobre la materia, y poco después, el 25 de noviembre, hacia lo propio el representante Santiago Albarracín.

Mientras tanto, en el orden nacional, el $1 .^{\circ}$ de mayo de $\mathbf{1 8 5 3}$ era sancionada en Santa Fe la Constitución, cuyo artículo $5 .^{\circ}$ se limita escuetamente a imponer a las Provincias la obligación de asegurar el régimen municipal. Con esta imposición los constituyentes declaraban implícitamente la existencia y necesidad natural del Municipio, al que solamente había que dar un determinado régimen jurídico. Posiblemente los constituyentes consideraron también que no era conveniente dar normas uniformes para la organización de los Municipios en todo el país. Esta solución, inspirada en la pureza de los principios federalistas, ya no se podría mantener hoy en todo su rigor después de la experiencia de nuestra vida municipal y ante el estado de los principios sobre el punto. Es indispensable incluir en la Constitución bases que aseguren a las Municipalidades un grado suficiente de "autonomía" política, financiera y administrativa como para poder cumplir sus fines propios.

Los constituyentes tuvieron ocasión de expresar con más amplitud su pensamiento sobre la materia en los fundamentos del proyecto y en la consiguiente Ley que sancionaron el 6 de mayo de 1854, para la ciudad de Buenos Aires, estableciendo para la 
misma una Municipalidad electiva. Reproducía con pocas variantes e: Decreto del General Urquiza del año anterior, y, como éste, tampoco llegó a aplicarse (18).

Por esos días (septiembre de 1853), Sarmiento publicaba en Chile sus Comentarios de la Constitución de la Confederación Argentina, y, al ocuparse de la cláusula constitucional que impone a las Provincias asegurar su régimen municipal, nos ofrece su concepción de lo que debe ser una Municipalidad (19).

Por su parte, los gobernantes y la Prensa de Buenos Aires tampoco olvidaban el: asunto. En el mensaje leido ante la Legislatura el $1 .^{\circ}$ de octubre de $\mathbf{1 8 5 3}$, el Gobernador D. Pastor S. Obligado destacaba la necesidad de dictar la Ley de Municipalidades. Este pedido era renovado veinte días más tarde en un mensaje especial. El 28 del mismo mes, el representante Domingo Olivera presentó a la Legislatura un proyecto sobre Municipalidades de campaña (20).

En estos momentos, también Bartolomé Mitre se interesa por el problema, y vuelca toda la fuerza de sus reflexiones en el gran trabajo sobre La reorganización de las Municipalidades de la Provincia, publicado en el periódico "El Nacional”, de Buenos Aires, el 22 de noviembre de ese año.

Le siguen trabajos de otros escritores. "La Tribuna", dirigida por J. R. Muñoz, empieza a publicar, el 8 de diciembre, un proyecto de Ley de Municipalidades. En el mismo periódico, a partir del 12 de diciembre de 1853, Miguel Valencia publica siete artículos sobre el tema, y, poco después, un proyecto de Ley.

El extenso estudio de Mitre, en el que se combina la visión

(18) En los fundamentos del proyecto se decía: El sistema municipal, palanca del progreso material y de la buena policia de las ciudades, es de esperar que se extienda a toda la República y que sea consignada en las cartas provincialess. Y se confiaba en que la Ley para la ciudad de Buenos Aires aprobablemente servirá de modelo para establecer Municipalidades en toda la Repúblican.

(19) En đObras completasn, t. VIII, pág. 241.

(20) Ver Carlos Heras, Antecedentes sobre la instalación de las Municipalidades e* la Hrovincia de Buenos Aires (1852/54), en CTrabajos y comunicaciones», publicación del. Instituto de Investigaciones Históricas en la Facultad de Humanidades de la Universidad Nacional de La Plata. 1948, t. I, págs. 75 y siguientes. 
del historiador y el realismo del hombre de gobierno, tiene importancia como programa de acción gubernativa. Ya había publicado otro artículo sobre la matería en el mismo periódico "El Nacional", el 20 de octubre de 1852, bajo el título $E l$ gobierno de lo propio.

Para Mitre, la instalación de las Municipalidades debía ser considerada dentro de un plan más vasto, que era el de la reorganización de la administración de la Provincia, a cuyo efecto proponía la sanción de una Ley sobre el régimen interior (21).

Demostró tener el concepto preciso de la "autonomía" municipal, al decir que 1a Municipalidad ues el sistema del propio gobierno aplicado a la localidad". Esto significa la elección popular de sus autoridades; 1a libre gestión de los asuntos de su competencia, y el establecimiento, recaudación e inversión de sus rentas. Estaba convencido Mitre de que la elección directa de los municipales "constituye el nervio y la peculiaridad del poder municipal, sin cuyo requisito deja de ser poder...n. Preveía los males de la centralización, al decir que "la absorción del poder central paraliza la marcha de las localidades" (22).

Los fines de las Municipalidades eran variados: el adelanto moral, las mejoras económicas y el desarrollo industrial de las localidades, la dirección exclusiva de los intereses comunales, la aplicación de ciertas disposiciones generales, el cumplimiento de algunas obligaciones políticas, la ejecución de las leyes y reglamentos de policía o de utilidad comunal. $Y$ estos fines daban lugar $\mathbf{a}$ un conjunto numeroso de atribuciones.

al mencionar entre los fines de las Municipalidades el adelanto económico y el desarrollo industrial de las localidades, anticipándose a conceptos de nuestros días, entrevió la función

(21) Esta terminología fué recogida en la Constitución de la Provincia de Buenos Aires de 1873, cuyo artículo 109 establecia: aEl territorio de la Provincia será divid:do en distritos para su administración interior, que estará a cargo de las Municipalidadess.

(22) Bien dice hoy el ilustre profesor Carlos Ruiz del Castillo alo que los hombres pueden alcanzar por medio de la institución más próxima no debe encomendarse a los más alejados de nuestras actividades personales e inmediatas» (Presencia del Municipio, Madrid, 1957, pág. 51). 
económica de esas instituciones. Ya Echeverria incluia entre los fines del Municipio el fomento de las industrias agrícalas y ganaderas, y, por su parte, Alberdi lo consideraba como un pèqueño "poder económico".

Al comparar el ámbito de actuación-que la Ley deja hoy a nuestras Municipalidades-con la que Mitre les asignaba en su época-dentro de una sociedad y de una vida urbana más sencilla-, aquél nos parece proporcionalmente más reducido. Ello se debe en buena parte a que antiguos servicios municipayes son hoy prestados o regu'ados por otros organismos (enseñanza primaria, aguas corrientes, transportes urbanos, beneficencia, etc.).

Dentro de la organización institucional de la Provincia dé Buenos Aires, la Municipalidad era, para Mitre, el cuarto poder del Estado, aunque no un poder político (23). Advertía sobre los pe'igros de convertir los órganos de'iberantes de las Municipalidades en asambleas esencialmente políticas, atentas a asuntos reservador por su naturaleza, a las legislaturas. Ello tuvo sentido en el antiguo Cabildo, en el cual, por no existir las 'egislaturas, se' reconcentraba la vida política. Las funciones de las Municipalidades debían ser esencialmente administrativas y económicas. Ello no significa que el gobierno municipal carezca de "su política) para realizar esa acción administrativa y económica en su esfera propia de actuación, es decir, sin sometimiento a otros. poderes, pero también sin pretensión de ejercer política privativa de esos poderes. La injerencia de las Municipa:idades en: cuestiones politicas nacionales o provinciales, aunque invoquen justas causas en nombre del pueblo, puede acarrearles, como a los antiguos Cabildos que caigan "postradas por sus fatigas, a la par que por sus excesos".

(23) Esta concepción de la Municipalidad como un poder del Estado fué generalmente aceptada por los pub'icistas argentinos durante un buen tiempo. Después de 1873 se nota la influencia de la terminologia empleada por la Constitución de la Provincia de Buenos Aires que se refiere a! régimen municipal y no. al poder municipal (ver Carlos Moucher, Florentino González, primer profesor de. Derecho constitucional de la Universidad de Buenos Aires y sus ideas sobre el régimen municipal, en Revista de la Facultad de Derecho y Ciencias Sociales», Buenos Aires, 10̄̄i núm. 25, págs. 785 y siguientes). 
Después de formular una crítica, por su sentido centralizador, al Decreto de Urquiza, del 2 de septiembre de 1852, sobre el régimen municipal para la ciudad de Buenos Aires, analiza los dos proyectos sobre la materia pendientes en la Legislatura de la Provincia, de que eran autores, respectivamente, los diputados Estévez Seguí y Olivera. También está en desacuerdo con ellos, por su orientación centralista.

En su estudio, advertía Mitre que no bastaba establecer las Municipalidades. Conjuntamente era necesaria la reforma del orden administrativo de la Provincia, creando una organización descentralizada, que no existía entonces, pues en las parroquias y distritos de la campaña la única autoridad-elegida por el gobierno provincial-era el Juez de Paz. La Administración debía ser central, departamental y municipal. $\mathrm{Y}$ tanto el Departamento como la Municipalidad debía tener, en pequeño, la misma organización que el gobierno central.

En cada Departamento debía existir un Intendente o Jefe político, designado por el Ejecutivo, y una Junta administrativa del Departamento, elegida popularmente. En cada distrito habría un Juez de Paz, nombrado por el pueblo, sin perder su carácter de agente del Poder central, y una Municipalidad eiectiva, que podria ser rústica o urbana. Comprendiendo que sin bases económicas y financieras no hay instituciones municipales con vida propia, proponía dotarlas de los recursos necesarios para que fueran ricas. Proponia entregarles en propiedad los ejidos de los pueblos, el usufructo de las propiedades públicas existentes dentro de su demarcación y adjudicarles, dentro del área de los pueblos, cuatro manzanas para la instalación de establecimientos públicos, útiles o piadosos. Además, se les facultaba el cobro de diversos impuestos y un porcentaje de la contribución directa, cuya recaudación estaría a su cargo.

Se declara partidario de la intervención de los extranjeros en el gobierno municipal. Fundaba esta idea en que los extranjeros tienen intereses que hacer valer en la comunidad administrada por la Municipalidad; que constituia un deber de justicia hacia quienes habian cooperado en la independencia y progreso del país $y$, finalmente, por estar familiarizados en sus tierras de ori- 
gen con las instituciones municipales, to que no sucedía con la gran mayoría de los hijos del país.

A pesar de todo el movimiento en favor de la sanción de 1a Ley de Municipalidades para la Provincia de Buenos Aires, este acontecimiento no llegó a producirse en el año 1853.

Poco después, a principios de 1854, producida la secesión del Estado de Buenos Aires, éste dictaba su Constitución, cuyo artículo 170 establecía : "El régimen municipal será establecido en todo el Estado. La forma y elección de los Municipios, las atribuciones $\mathrm{y}$ deberes de estos Cuerpos, como todo to relativo a sus rentas y arbitrios, serán fijados en la Ley sobre la materia).

Al discutirse esa norma de la. Constitución de Buenos Aires, Mitre señaló con axierto que la misma adolecía de la deficiencia de no sentar algunos principios generales del régimen municipał, que quedaba, así, librado a la discrecionalidad del Gobierno (sesión del 2 de marzo de 1854, en la Sala de Representantes). Formulaba así una crítica, también valedera para el artículo $5^{\circ}$ de la Constitución Nacional, sancionada el año anterior, y se anticipaba a la concepción actual de que la Constitución debe contener un mínimo de bases políticas, financieras y administrativas de la autonomía municipa!, sin perjuicio de dejar cierto margen de discrecionalidad a las Provincias para establecer 1a organización de las Comunas.

Sólo el 11 de octubre de 1854 la Provincia llega a dictar su Ley de Municipalidades para la ciudad de Buenos Aires y la campaña, basada principalmente en el Decreto de Urquiza, de , 1852, y en el proyecto de Olivera (24). Merece recordarse, por su elevado sentido doctrinario, el discurso que el senador Valentín Alsina pronunció en la Legislatura el 10 de octubre de

(24) Ver Carlos Mouchet, El centenario de la Ley de Municipalidades de la Provincia de Buenos Aires de 1854, en revista dLa Leyn, enero-marzo 1950̄, t. 77 , página 771. Este trabajo se publicó parcialmente en la aRevista del Instituto de Historia del Derechop, Buenos Aires, 19:54, núm. 6. El Consejo municipal de la ciudad de Buenos Aires se instaló el 3 de abril de 1866, transcurridos treinta y cinco años desde la abolición del Cabildo. 
1854, al aconsejar la aprobación del proyecto de Ley. Criticó el sistema centralista de la Administración, que "se hallaba arraigado de tal modo en las ideas y en los hábitos del país, que la generalidad encontraba naturalísima la inmovilidad local, mientras no mediase el impulso directo de la autoridad supreman. Se refirió a la necesidad y ventajas del régimen municipal, pero también marcó los límites de la institución frente al Estado nacional o provincial. También procuró calmar la desconfianza e inquietud de otros legisladores que temían una excesiva independencia de las Municipalidades o un uso indebido de sus facultades, declarando, por el contrario, que era preciso uinocularles el sentimiento de su propia importancian.

Fué desoída la idea fundamental de Mitre sobre el' gobierno de lo propio, pues el Presidente de la Municipalidad de la capital era el Ministro de Gobierno de la Provincia, quedando así sujeta la Corporación al Poder central (25). Tampoco se tuvo en cuenta el consejo sobre la división de la Provincia en Departamentos, y de éstos en distritos municipa?es, que después fué adoptada con éxito en otras Provincias. El sistema del Partido-Municipio adoptado en la Provincia de Buenos Aires, y que sigue en vigencia en la misma, no se adecúa al concepto de la vida municipal, pues, cuando en un Partido o Departamento hay varios centros urbanos, el que es cabeza de Partido goza de una situación privilegiada, en tanto que los otros quedan en estado de dependencia y quizá paralizados en sus posibilidades de desarrollo. Este sistema, adoptado, además de Buenos Aires, por las Provincias de Mendoza y San Juan, ha sido objeto de fundadas críticas por autores contemporáneos (26).

Lo que bien podríamos llamar la "modernidad" del pensamiento de Mitre sobre el Municipio, nos permite revivirlo con gusto y partir de él como sustento de meditaciones para el tiempo presente.

(25) Ver Carlos Mouchet, El contenario de la Ley de.Municipalidades de la Provincia de Buenos Aires de 185/, en revista «La Leys, Buenos Aires, t. 77, eneromarro 19ōõ, págs. 771 y siguientes.

(26) Confr. Faustino J. ILEGón, Antreproyecto de Constitución para Méndoza, Büenos Aires, 1943, pág. $46 \pi$. 